\title{
Characterisation of non-histone nuclear proteins cross reactive with purified rheumatoid factors
}

\author{
J C MASON, P J W VENABLES, P R SMITH, AND R N MAINI \\ From the Kennedy Institute of Rheumatology, 6 Bute Gardens, London W6 7DW
}

SUMmARY In order to examine the interactions between isolated rheumatoid factors (RFs) and cell nuclear antigens we have prepared 10 RFs by affinity chromatography against IgG coupled to Sepharose. Of these, seven cross reacted with cell nuclei on indirect immunofluorescence. The nuclear antigen appeared to be DNA histones by indirect immunofluorescence on rat liver, though on immunoblotting the rheumatoid factors also reacted with three non-histone polypeptides which were identified in the soluble fraction of nuclear extracts. We were unable to show any relationship between these polypeptides and rheumatoid arthritis nuclear antigen. These reactions represent a hitherto unrecognised phenomenon, which extends the range of antigens recognised by rheumatoid factors. We suggest that the immunopathogenic significance of RFs may not be restricted to their reactivity with $\mathrm{IgG}$, and that non-histone nuclear proteins merit further investigation.

Key words: cross-reactive rheumatoid factors, immunoblotting.

The cross reactivity of isolated IgM rheumatoid factors (IgM RFs) with both the Fc portion of IgG and a cellular nuclear antigen has been reported by a number of groups. ${ }^{1-5}$ On indirect immunofluorescence IgM RFs react with rat liver cell nuclei to give a homogeneous staining pattern which can be inhibited with aggregated human IgG, Fc fragments, and rat liver chromatin, ${ }^{46}$ suggesting that the reaction is due to RFs rather than contaminating IgM antinuclear antibodies (ANA). Several workers ${ }^{1-5}$ have also provided evidence against the possibility that IgG ANA copurifying with RF may act as a bridge for the secondary binding of RF to the Fc portion of IgG ANA. The only evidence against the participation of $\mathrm{Clq}$, which binds directly to $\mathrm{DNA}^{7}$ and to IgG affinity columns, ${ }^{8}$ has been the lack of effect of heating the RF preparations to $56^{\circ} \mathrm{C}$ and lack of reactivity when anti-C1q conjugates were used. ${ }^{16}$

There is good evidence that deoxyribonucleic acid (DNA) histones bind IgM RFs, as shown by inhibition studies with nucleosomes and DNAhistones, ${ }^{3910}$ by acid elution ${ }^{11}$ and reconstitution on

Accepted for publication 16 November 1984.

Correspondence to Dr P J W Venables. tissue sections, ${ }^{1}$ and by direct binding in an enzymelinked immunoadsorbent assay. ${ }^{10}$ However, Johnson ${ }^{12}$ has suggested that the cross reaction may be an ionic interaction with free basic groups and may be of little immunopathological significance.

Recently the technique of immunoblotting has been used to show the reactivity of polypeptides with sera containing antibodies to soluble nonhistone proteins, ${ }^{13} 14$ including rheumatoid arthritis nuclear antigen (RANA) which migrates as a doublet with a molecular weight of 80000 and is present in Epstein-Barr virus (EBV) transformed cells. ${ }^{15} 16$ However, the nature of the antigen(s) reactive with RFs has not been examined by this method, and there is no data about a possible relationship with RANA.

In this study immunofluorescence was used to investigate a possible role for $\mathrm{Cla}$ and other immune reactants in the binding of rheumatoid factors to nuclei. All investigations were performed in isotonic saline at a physiological $\mathrm{pH}$ in an attempt to minimise non-specific interactions. In addition we have adapted the immunoblot technique to examine the possibility that a non-histone protein may represent the specific antigen reactive with RFs and to investigate whether it is related to RANA. 


\section{Materials and methods}

IgM RF PREPARATIONS

Sera from eight patients with rheumatoid arthritis (RA), and one matched synovial fluid were selected on the basis of high titre rheumatoid factors. Serum from a patient with a polymyositis/scleroderma overlap syndrome, i.e. mixed connective tissue disease (MCTD), was chosen as a control on the basis of an IgG ANA titre of greater than 1/128 000 and a RF titre of $1 / 160$ by latex agglutination. Cyanogen bromide activated Sepharose (Pharmacia Great Britain, Hounslow, Middlesex, UK) was prepared according to the manufacturer's instructions, and purified IgG (Miles, Stoke Poges, UK) was coupled at $20 \mathrm{mg} \mathrm{IgG/g}$ Sepharose for two hours at room temperature. After blocking for two hours at room temperature with $0.2 \mathrm{M}$ glycine $\mathrm{pH} 8.0$ the gel was packed as $15 \mathrm{ml}$ columns in $30 \mathrm{ml}$ syringes. The columns were washed with three cycles of $0 \cdot 1 \mathrm{M}$ bicarbonate, $0 \cdot 5 \mathrm{M} \mathrm{NaCl}, \mathrm{pH} 8 \cdot 3 ; 0 \cdot 1 \mathrm{M}$ glycine, $0 \cdot 5$ $\mathrm{M} \mathrm{NaCl}, \mathrm{pH} 2.5$; and $3 \mathrm{M}$ guanidine hydrochloride. Immediately before use the columns were washed extensively with $0 \cdot 15 \mathrm{M}$ phosphate-buffered saline (PBS) $\mathrm{pH} 7 \cdot 4.5 \mathrm{ml}$ of serum was applied to the column over two hours and washed slowly through with PBS. The column was washed with three column volumes of PBS, and the RF was eluted with $20 \mathrm{ml} 1.5 \mathrm{M}$ guanidine hydrochloride. After dialysis at $4^{\circ} \mathrm{C}$ against PBS with three buffer changes the KF's were analysed by latex agglutination, and IgM and IgG concentrations were determined by radial immunodiffusion.

\section{IMMUNOFLU ORESCENCE}

Fluorescein isothiocyanate conjugated (FITC) goat antisera specific for human immunoglobulin, $\gamma$ and $\mu$ chains and $\mathrm{C1q}$ (Behringwerke, Marburg, FRG) were obtained commercially. FITC rabbit antihuman fibrinogen, Cls, and C3, were kind gifts from Dr David Woodrow, Experimental Pathology, Charing Cross Hospital Medical School. Human C1q was purified by the method of Zubler et al. ${ }^{17}$ ANA activity was studied by indirect immunofluorescence on cryostat tissue sections of rat liver (Bio-Dx), mouse kidney (Kallestad, FRG), and acetone/methanol fixed $\mathrm{Hep}_{2}$ cells as previously described. ${ }^{18} 20 \mu \mathrm{l}$ of isolated IgM RF was incubated at room temperature in a moist chamber for 30 minutes. After incubation slides were washed for 10 minutes with PBS pH $7 \cdot 4$, incubated as before with the appropriate FITC antisera for $\mathbf{3 0}$ minutes, and then washed for 10 minutes in PBS. Slides were mounted in $90 \%$ glycerol/PBS and viewed with a Leitz Laborlux $12 \mathrm{UV}$ microscope. In order to investigate possible direct binding of $\mathrm{Clq}$ the method was repeated using purified $\mathrm{C} 1 \mathrm{q}\left(10 \mathrm{mg}-1 \frac{\mathrm{O}}{\mathrm{f}}\right.$ $\mathrm{g} / \mathrm{l})$ as the first layer and developed with an anti-C1q? FITC conjugate.

Inhibition studies were performed with an equato volume of $\mathrm{IgG}$, aggregated $\mathrm{IgG}$ (heated at $63^{\circ} \mathrm{C}$ foro 30 minutes), $\mathrm{C} 1 \mathrm{q}$, washed and pelleted latex $\mathrm{IgG}, 1$, protamine sulphate, and purified histones (Sigma $\mathbb{\Omega}$ Poole, Dorset, UK), all in PBS, by prior incubationo with IgM RF for $30 \mathrm{~min}$ at $37^{\circ} \mathrm{C}$. They were then examined for ANA activity with FITC antihuman IgM. Rat liver sections were depleted of histones by $\vec{\overrightarrow{ }}$ washing with $0 \cdot 1 \mathrm{M} \mathrm{HCl}$ and reconstituted with $25 \mathrm{\omega}$ $\mathrm{mg} / \mathrm{l}$ of histones as described by Tan et al. ${ }^{11}$

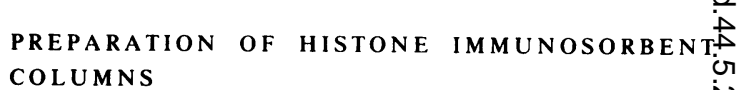

$2.5 \mathrm{~g}$ of DNA-cellulose (Sigma) was washed in $1 \mathrm{M}$ $\mathrm{NaCl}$ for five minutes at room temperature and foro 40 minutes in PBS. The DNA-cellulose was mixed for one hour with a $1 \mathrm{~g} / \mathrm{l}$ solution of whole histonesz (Sigma) in PBS. After a further wash in PBS the get was packed into a $10 \mathrm{ml}$ column. $10 \mathrm{ml}$ of isolated $\vec{c}$ RF was passed through the column for two hours, of washed through with PBS, and a $10 \mathrm{ml}$ eluate was collected. The column was eluted with bicarbonateo buffer $\mathrm{pH} 8 \cdot 3,0.5 \mathrm{M} \mathrm{NaCl}$ and glycine buffer $\mathrm{pH}$ 2.5 , and $0.5 \mathrm{M} \mathrm{NaCl}$, and the $10 \mathrm{ml}$ sample waso dialysed overnight against PBS. Both the flow: through, containing unbound material and the eluate containing RF which had bound histones $\overrightarrow{\vec{O}}$ were analysed for RF titre by latex agglutination 3 and for cross reactivity by immunofluorescence and the Western blot.

SODIUM DODECYL SULPHATE (SDS)

POLYACRYLAMIDE GEL ELECTROPHORESIS

(PAGE) AND WESTERN BLOT

$5-15 \%$ gradient gels ( $\mathrm{pH} 8 \cdot 8$ ) with a $4 \%$ stack ( $\mathrm{pH}$ 6.8) were run as vertical slabs $170 \mathrm{~mm} \times 150 \mathrm{~mm} \times$ $1.5 \mathrm{~mm}$ according to the method of Laemmli. ${ }^{19} \mathrm{O}$ Nuclear or whole cell extracts for blotting were $>$ prepared by sonication in PBS as previously․ㅡ․ described. ${ }^{15}$ After centrifugation at $20000 \mathrm{~g}$ then supernatant of the sonicate was retained as the normal saline extract, and the pellet then sonicated in $1 \mathrm{M} \mathrm{NaCl}$ to provide a histone-enriched (highw salt) extract. Samples for electrophoresis were boiled for five minutes in sample buffer containinge $1 \%$ SDS and $0 \cdot 1 \mathrm{M}$ dithiothreitol.

Proteins separated by SDS PAGE were trans- $\stackrel{\infty}{+}$ ferred to nitrocellulose paper (Schleicher and Schull, $\frac{T}{\top}$ Dassell, Germany) in a Biorad Transblot cell

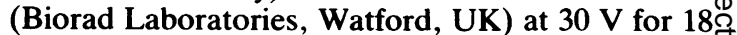
hours in 0.025 M trometamol (TRIS) and 0.192 $\mathrm{M}_{\Omega}^{\mathbb{Q}}$ glycine containing $20 \%$ methanol by a method based on that of Burnette. ${ }^{20}$ After blocking with $2 \%$ casein $\cap$ 
in PBS for two hours the sheets were incubated with isolated IgM RF diluted 1:2 with $\mathrm{PBS} /$ casein for one hour at room temperature. The sheets were washed four times for $15 \mathrm{~min}$ in PBS and incubated for one hour in antihuman IgM (Dako, Copenhagen, Denmark) labelled by the chloramine$T$ method $^{21}$ and diluted in PBS/casein. After a further four washes in PBS the sheets were dried and developed by autoradiography for 72 hours.

For identification of proteins within the IgM RF preparations the eluates were separated by SDS PAGE, transferred, and incubated as above with antihuman $\operatorname{IgM}$, $\operatorname{IgG}$, or $\operatorname{IgA}$, antihuman $\mathrm{Clq}$, antihuman $\mathrm{C} 3$, or antihuman fibrinogen diluted $1: 100$, washed as above, and incubated for one hour with ${ }^{125}$ I-protein A labelled by chloramine- $\mathrm{T}$, followed by further washes and development by autoradiography for 18 hours.

\section{Results}

The protein concentrations of the isolated IgM RFs were from 0.02 to $0.35 \mathrm{~g} / \mathrm{l}$ and they were all positive

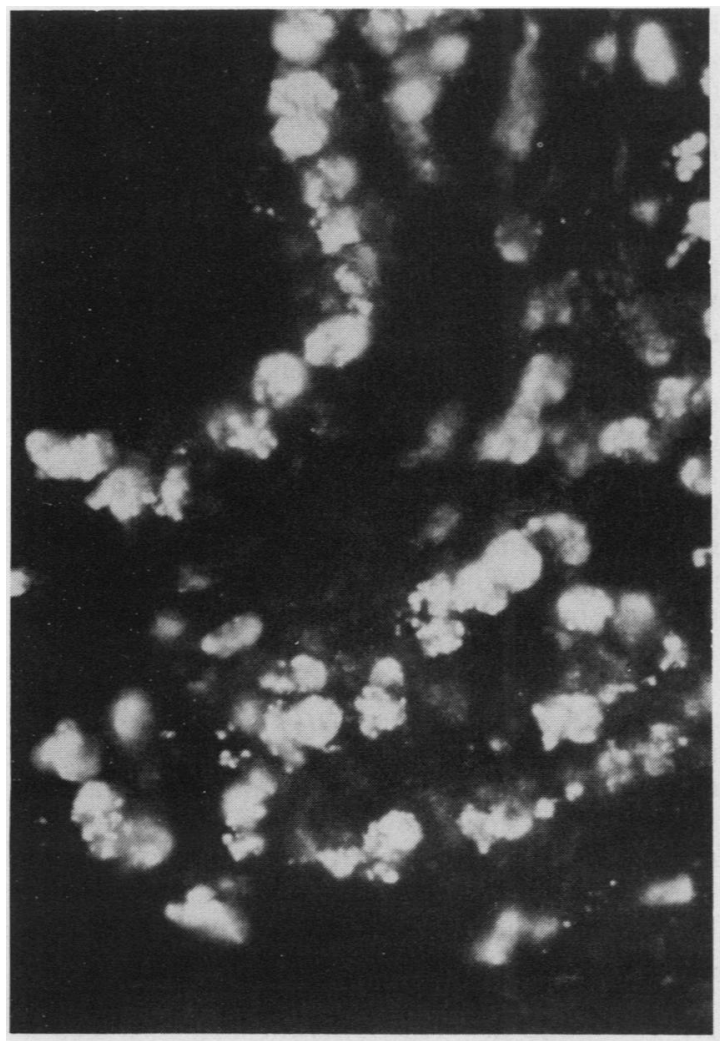

Fig. 1a by latex agglutination, with titres varying from $1: 32$ to $1: 256$. On indirect immunofluorescence for antinuclear antibody activity with FITC antihuman IgM seven (including the RF from the synovial fluid) out of 10 RFs gave nuclear staining, with a mean titre of $1 / 64$. The nuclear staining pattern was homogeneous on rat liver and mouse kidney sections, but a more granular pattern was seen with $\mathrm{Hep}_{2}$ cells (Fig. 1). Latex IgG and aggregated IgG at two different concentrations completely inhibited the cross reaction on indirect immunofluorescence (Fig. 1c). Monomeric IgG, free histones, and protamine partially inhibited the cross reaction, and $\mathrm{Clq}$ had no effect. Passage of the IgM RF down a DNAcellulose-histone column before immunofluorescence abolished cross reactivity, which could be recovered from the eluate as homogeneous nuclear staining. Two RFs, both negative for IgM ANA, showed evidence of IgG ANA at titres of $1 / 2$ and 1/8. One of these was from the MCTD patient whose serum IgG ANA titre was greater than $1 / 128000$.

The concentration of IgM in the dialysed eluates

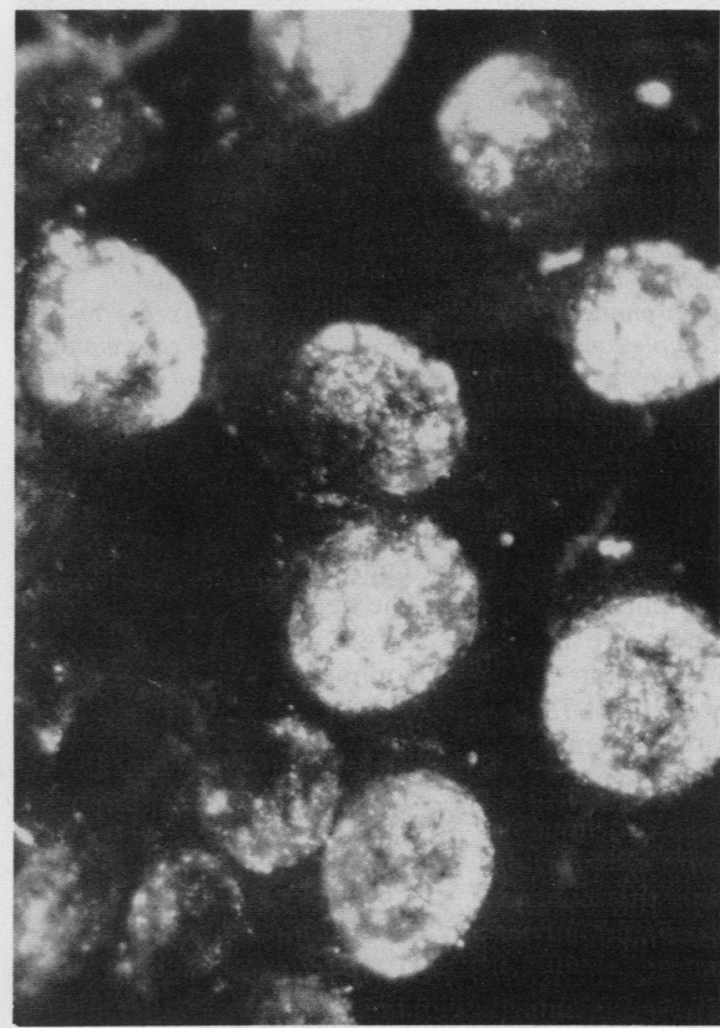

Fig. 1b 


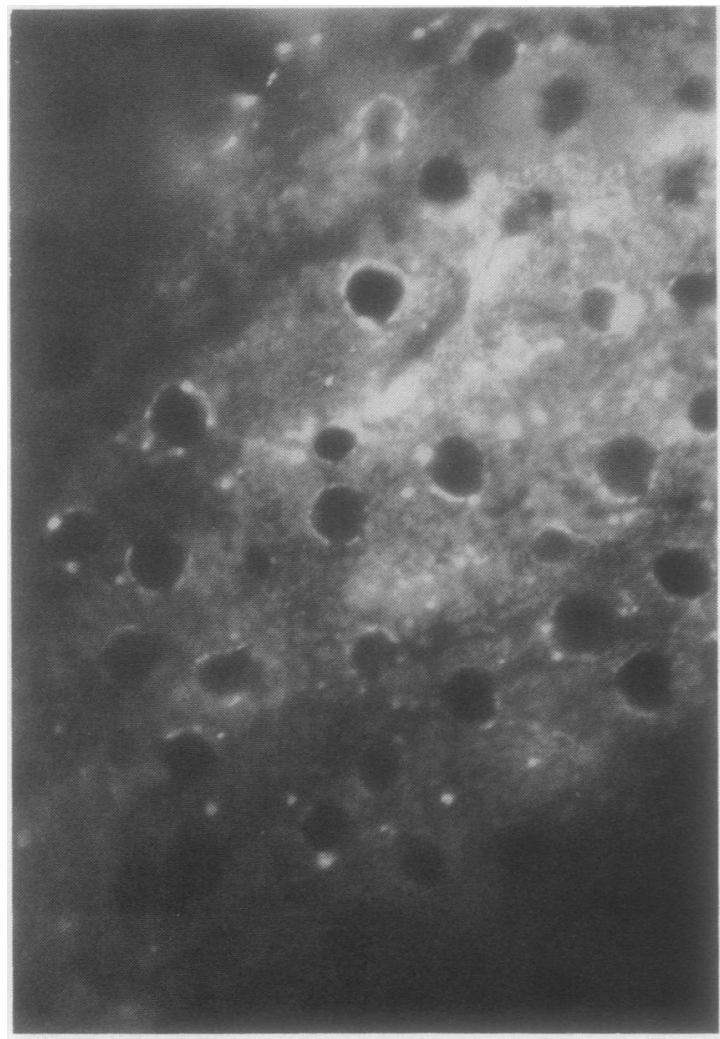

Fig. 1c

Fig. 1 Indirect immunofluorescence with a purified rheumatoid factor developed with FITC anti-IgM: (a) homogeneous nuclear staining on rat liver; (b) an amorphous granular staining pattern on $\mathrm{Hep}_{2}$ cells; (c) complete inhibition by aggregated IgG of nuclear staining shown as unstained 'holes' against background cytoplasmic staining on rat liver. $(\times 425)$.

varied from 0.0135 to $0.29 \mathrm{~g} / \mathrm{l}$ in approximately 20 $\mathrm{ml}$, with the mean total IgM yield being $0.79 \mathrm{mg}$, accounting for approximately $70 \%$ of the protein in the purified material. The heavy and light chains of IgM were identified as two major bands on polyacrylamide gel electrophoresis, with molecular weights of 78000 and 32000 (Fig. 2). The identities of other minor components seen on the gel were confirmed by the Western blot with specific antisera (not shown). RF I and II contained the C3 complement component at 75000 . The minor band at 62000 was the $\operatorname{IgA}$ heavy chain, and the 52000 band in the IgM RFs corresponded to the IgG heavy chain. All the RFs contained an unidentified 41000 band which did not react with an antifibrinogen serum. RFs I, II, and III showed a 31000 band corresponding to C1q. Because RFs I, II, and III

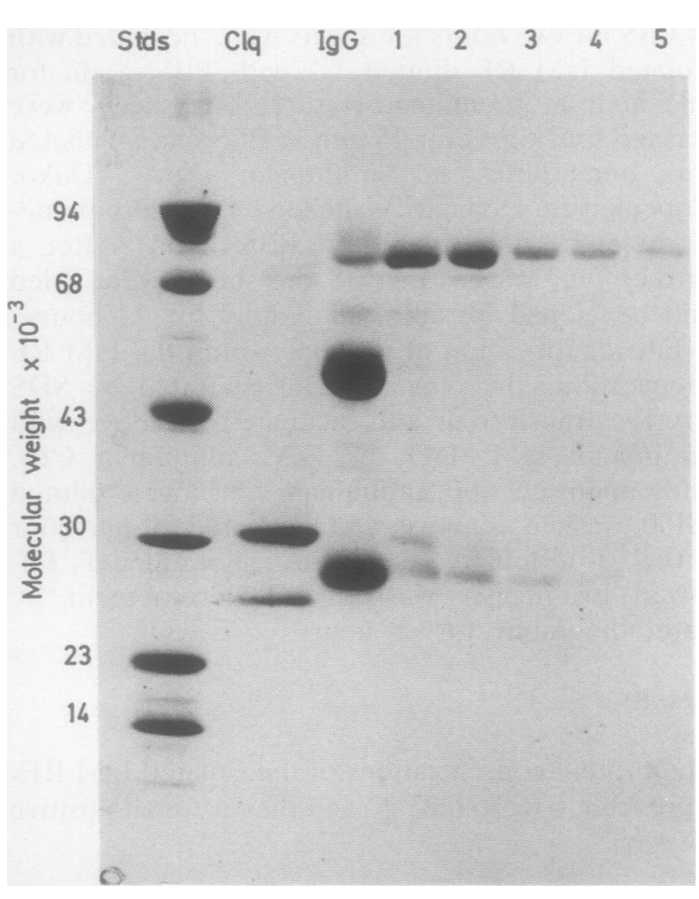

Fig. 2 Polyacrylamide gel electrophoresis, samples stained with Coomassie Blue, showing molecular weight standards $\overline{0}$ (stds), the polypeptides of purified $\mathrm{Clq}$ (the same material that was used in the inhibition and absorption experiments), $\operatorname{IgG}$, and five purified rheumatoid factor preparations.

also contained the highest concentration of IgM they were selected for further studies with specificov conjugates.

No nuclear staining was seen with either fluor- $\frac{-}{3}$ escein conjugates of antibodies to the complementicomponents $\mathrm{Clq}, \mathrm{C} 1 \mathrm{~s}$, and $\mathrm{C} 3$ or with FITC antifibrinogen. Heating the RFs to $56^{\circ} \mathrm{C}$ did not diminish their ANA activity with the anti-IgM? conjugate. No specific staining was seen when the slides were overlaid with purified $\mathrm{Clq}$ in a range of dilutions from $10 \mathrm{mg} / \mathrm{l}$ to $1 \mathrm{~g} / \mathrm{l}$ and developed with anti-C1q.

\section{ANTIGENS REACTIVE WITH RHEUMATOID} FACTORS

Comparison of acid eluted and untreated rat livefo sections as a substrate for detection of the cross reaction of IgM RF showed that the cross reaction was completely inhibited by acid elution and par $\frac{0}{0}$ tially restored by reconstitution with histones (Fig $\underset{\stackrel{\mathbb{D}}{ }}{ }$ 3).

On Western blotting only one rheumatoid factor $\stackrel{\mathbb{D}}{\stackrel{Q}{Q}}$ RF I, showed any reaction with histones, seen aश faint bands between 14000 and 23000 in theo 


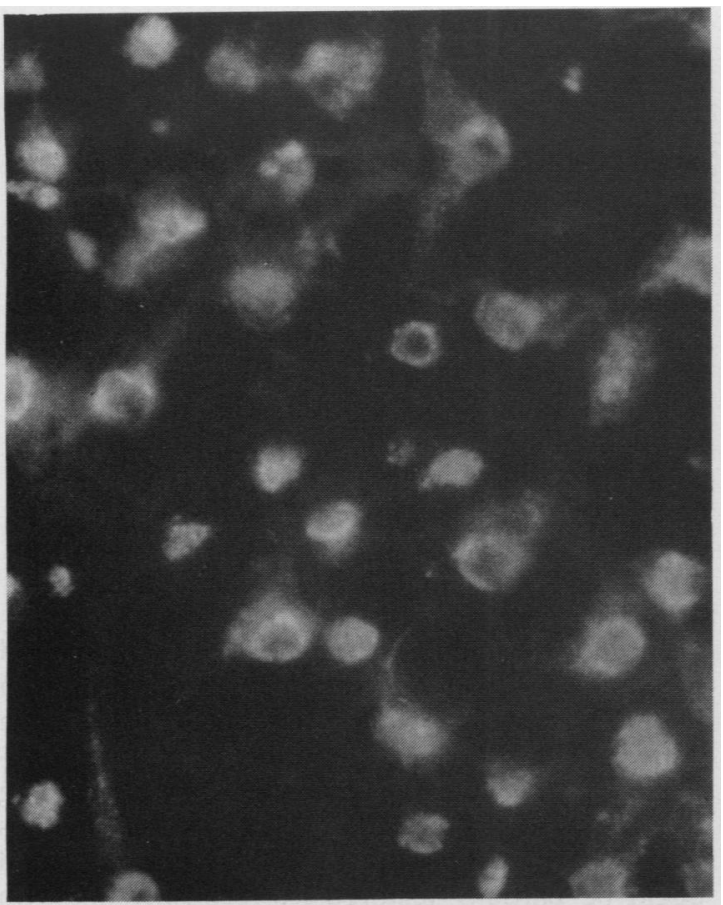

Fig. 3a

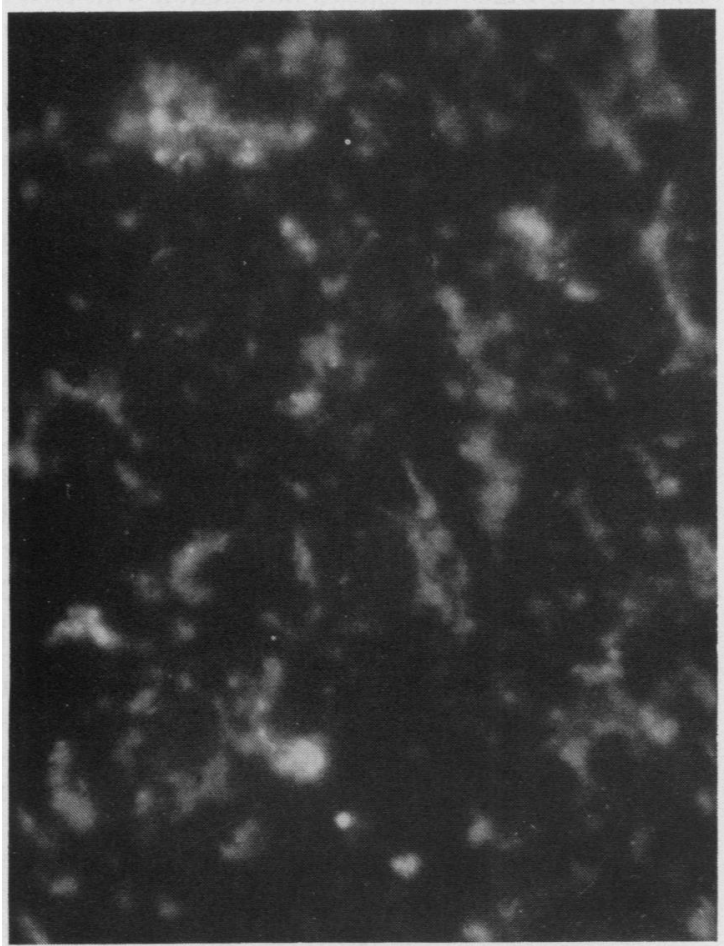

Fig. 3b

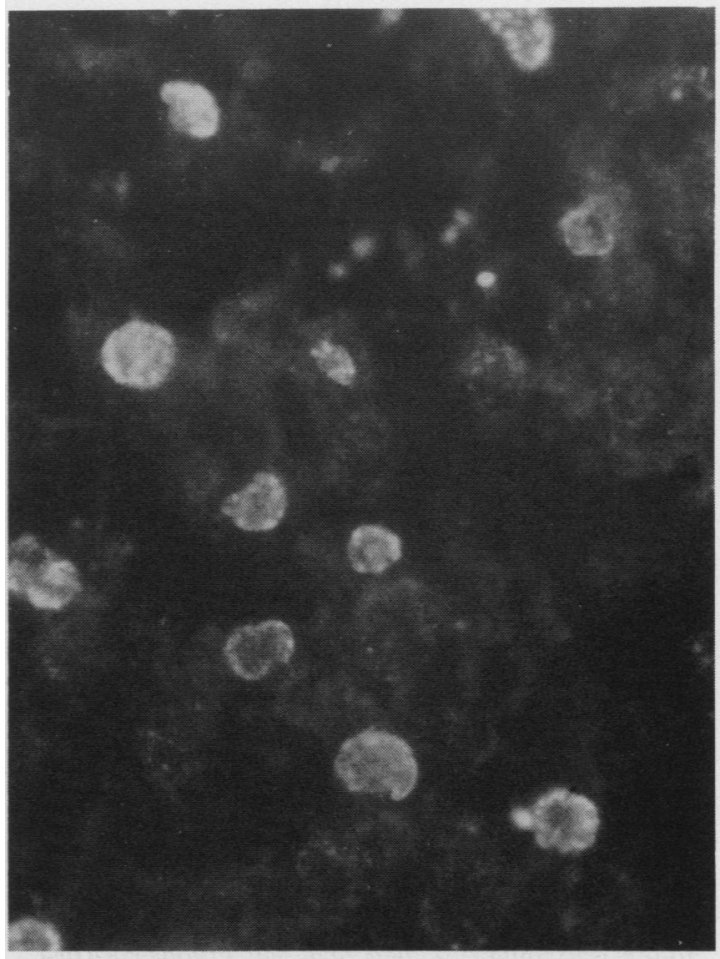

Fig. 3c

Fig. 3 Demonstration of reactivity between a purified rheumatoid factor and histones by depletion and reconstitution on rat liver using indirect

immunofluorescence. (a) Untreated section showing homogeneous and rim staining pattern by purified rheumatoid factor; (b) acid eluted section; (c) acid eluted section reconstituted with histones. $(\times 480)$.

purified histones and in the high salt cell extract. However, all three reacted strongly in the isotonic saline extract with a higher molecular weight (94000) polypeptide and relatively weakly with polypeptides of molecular weight 200000 and 48000 (Fig. 4). These polypeptides were seen in the EBV transformed B lymphoblastoid cell lines WiL2, Daudi, B958, Raji and in the EBV negative lines Ramos and Molt-4. The reactivity was the same with isolated nuclei as with whole cell extracts. Identical polypeptides were blotted in fresh rabbit thymus extract but not in a commercially available rabbit thymus acetone powder. The bands did not react with an isolated rheumatoid factor which had no ANA activity on immunofluorescence nor with the conjugate alone. No reactivity was seen when the blots were developed with anti-IgG or staphylococcal protein $\mathrm{A}$.

Recognition of the three bands by the rheumatoid 


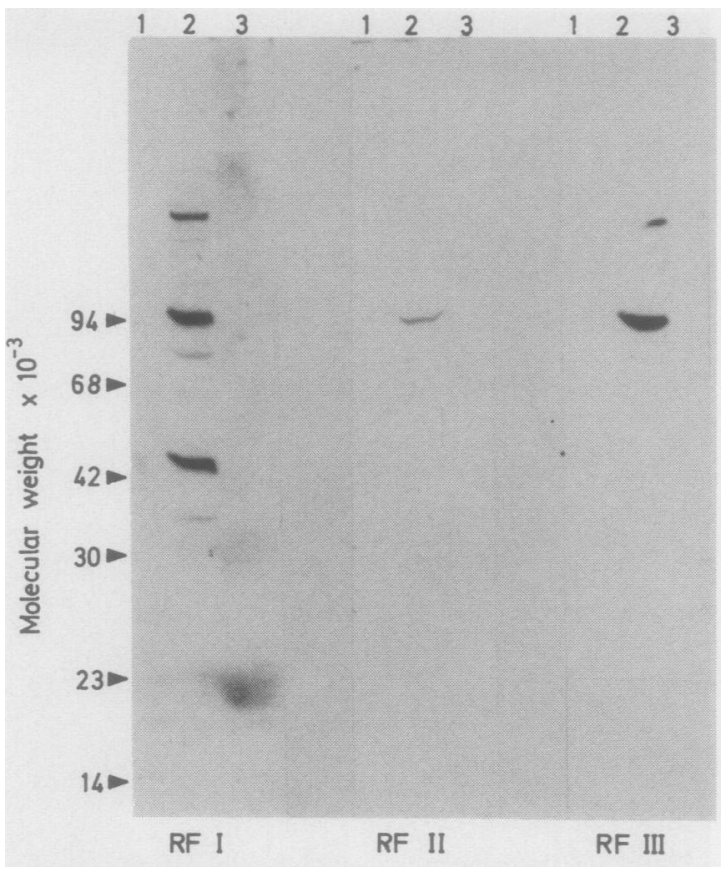

Fig. 4 Western blots by three purified rheumatoid factors RFS I-III on histones (lanes 1), isotonic saline extract of Molt-4 cells (lanes 2), and high salt histone-enriched extract (lanes 3).

factors was completely inhibited by aggregated IgG but not monomeric IgG. Absorption of RF I on the DNA-cellulose-histone column completely abolished the reaction, and the activity was recovered from the eluate.

\section{Discussion}

In this study we found cross-reactive RFs in six out of eight RA patients studied. This frequency (approximately $75 \%$ ) is in keeping with reports from Johnson ${ }^{4}$ but is much higher than that described by previous authors. ${ }^{1-3}$ However, our study was designed to examine immunochemical interactions between RFs and nuclear antigens rather than to investigate the prevalence of this phenomenon in an RA population, and we suggest that our high frequency was due to the deliberate selection of sera from patients with severe RA with high titre RFs and which (with one exception) were ANA positive.

Surprisingly, no previous study has published data on the examination of affinity purified rheumatoid factors by polyacrylamide gel electrophoresis. We found that in addition to IgM, IgG and complement components could be identified in our preparations.

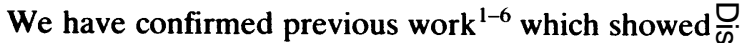
that the reactions were not due to $\mathrm{IgG}$, by using $\Rightarrow$ anti-IgG conjugates and by the lack of cross reactivity of a rheumatoid factor purified from ato patient with MCTD deliberately selected for the presence of very high titre IgG ANA. It is of interest $\frac{\bar{m}}{\frac{}{2}}$ that the low titre of ANA (1:8) within this RF preparation compared with serum IgG ANA® suggests that the maximum contamination of $\mathrm{IgG}_{\overrightarrow{ }}$ without RF activity in these eluates from the affinity? columns was less than $0 \cdot 1 \%$ after a single purifica- $\vec{\omega}$ tion step. With purified C1q we were unable to show any direct binding to cell nuclei. Heating the RF to $56^{\circ} \mathrm{C}$ had no effect on the reaction, and there was no nuclear fluorescence when FITC anti-C1q, anti-C1s, or anti-C3 were used as conjugates. This confirms is previous work ${ }^{16}$ that provided evidence against $\mathrm{C} 1 \mathrm{q} \stackrel{\infty}{\infty}$ mediating in a false positive reaction.

On indirect immunofluorescence the rheumatoid factors reacted with mouse kidney or rat liver nucleiz to give a predominantly homogeneous or rim pattern compatible with antibodies to DNA- $\vec{c}$ histones. This reaction was abolished by prewashingo or the slides with $0 \cdot 1 \mathrm{M} \mathrm{HCl}$, a procedure which elutes histones (as well as other nuclear antigens), ando could be partially restored by reconstitution with purified histones. This supports previously pub-o lished work which has shown interaction with DNA histones both by immunofluorescence ${ }^{1-5}$ and by solid phase assays. ${ }^{10}$ However, the granular pat- $\overrightarrow{\overrightarrow{0}}$ tern on $\mathrm{Hep}_{2}$ cells was quite unlike that seen with3 antihistone antibodies and suggested to us that additional reactivity with non-histone proteins could? be playing a part. This was supported by the reactions seen on the Western blot. Although? blotting of histones was seen with one of the RFs tested, the reaction was faint and was much lessio striking than that seen with three polypeptides of molecular weight 48000,94000 , and 200000 . These antigens were clearly not histones, as the molecular weight was too high (the largest histone $\frac{}{8}$ H1 migrates in SDS PAGE at mol. wt 31000 ) and they were present in an isotonic saline extract and $\mathbb{N}_{\sigma}$ not in the high salt (histone-enriched) extract. The relative lack of reactivity with histones on blotting could be due to their separation from DNA, which ${ }^{\omega}$ will occur after gel electrophoresis. This interpreta tion is supported by previous observations ${ }^{1}{ }^{4}$ that both DNA and histones are required for antigenicity, and by our findings that inhibition with DNA-cellulose-histone was complete and only partial with ${ }_{0}^{0}$ free histones.

Thus it appears that RFs bind to two different sets of antigens depending on the type of assay used:음 histones by immunofluorescence on rat liver and the higher molecular weight polypeptides on blotting. 
The blotting activity was completely inhibited by absorption with DNA-cellulose-histone and could be recovered from the eluate, suggesting that this dual reactivity was not due to different populations of RFs in our preparations. One explanation is that a major component of the immunofluorescent reaction is not due to histones but to the soluble polypeptides detected on blotting. This could explain the granular staining pattern on $\mathrm{Hep}_{2}$ cells, which is quite unlike the more homogeneous pattern seen with antihistone antibodies. The fact that the staining disappeared after elution with acid is not evidence against this interpretation, because a number of nuclear antigens are destroyed or eluted by this treatment. ${ }^{11}$ It is possible that histones cross react with these polypeptides by sharing antigenic determinants. Alternatively it is conceivable that the binding of the RFs to histones which was shown on the column by inhibition in solution, and to the histone reconstituted immunofluorescent slides was a non-specific interaction due to their highly basic charge, as suggested by Johnson. ${ }^{12}$ This interpretation is supported by our finding of partial inhibition of binding to nuclei by protamine, another basic protein. However, our studies were conducted in conditions deliberately designed to minimise such interactions by performing all assays at a physiological $\mathrm{pH}$ in normal saline, and unlike Johnson we did not see inhibition by monomeric IgG on blotting or immunofluorescence, indicating a higher avidity of RFs for nuclear antigens than free IgG, though it appeared to be lower than that for aggregated IgG.

A recent study has suggested ${ }^{22}$ that monoclonal rheumatoid factors prepared from a $\mathrm{MRl} / \mathrm{lpr}$ mouse reacted with a range of nuclear antigens, as determined by direct binding and inhibition assays. In our study we have extended the range of nuclear antigens recognised by human rheumatoid factors to include three soluble polypeptides which appeared to react with the population of RFs that also reacted with histones and IgG. So far we have not been able to show any relationship between these antigens and RANA or any other of the many antigens to which autoantibodies are found in RA. However, we suggest that the polypeptides recognised by RFs on the Western blot merit further investigation, and that the immunopathogenic significance of RFs may not be related solely to their anti-Fc activity.

We would like to thank the Arthritis and Rheumatism Council for their continued support and the Nuffield Foundation who funded a short-term grant to JCM. We also gratefully acknowledge expert technical assistance from Pat Mumford. Angela Horsfall, and Lindsay Roffe.

\section{References}

1 Agnello V, Arbetter A. Ibanez de Kasep G, Powell R, Tan
E M, Joslin F. Evidence for a subset of rheumatoid factors that cross-react with DNA-histone and have a direct cross-idiotype. $J$ Exp Med 1980; 151: 1514-27.

2 Hannestad K. Johannessen A. Polyclonal human antibodies to IgG (rheumatoid factors) which cross-react with cell nuclei. Scand J Immunol 1976; 5: 541-7.

3 Hannestad K. Certain rheumatoid factors react with both $\mathrm{IgG}$ and an antigen associated with cell nuclei. Scand J Immunol 1978; 7: 127-36.

4 Johnson P M. IgM-rheumatoid factors cross-reactive with IgG and a cell nuclear antigen: apparent masking in original serum. Scand J Immunol 1979; 9: 461-6.

5 Aitcheson C T, Peebles C, Joslin F. Tan E M. Characteristics of antinuclear antibodies in rheumatoid arthritis. Arthritis Rheum 1980; 23: 528-38.

6 Johnson P. In Panayi G S. Johnson P M, eds. Immunopathogenesis of rheumatoid arthritis. London: Reedbacks. 1978: 45-50.

7 Peltier A P. Cyna L. Dryll A. 'In vitro' study of a reaction between the complement system and cellular DNA. Immunology 1978; 25: 779-84.

8 Reid K B M. Preparation of Clq, a subcomponent of the first component of the classical pathway of complement. Methods Enzymol. 1982; 80: 16-25.

9 Hannestad K. Stollar B D. Certain rheumatoid factors react with nucleosomes. Nature 1978; 275: 671-3.

10 Hobbs R N, Lea D J, Phua K K. Johnson P M. Binding of isolated rheumatoid factors to histone proteins and basic polycations. Ann Rheum Dis 1983; 42: 435-8.

11 Tan C M. Robinson J. Robitaille P. Studies on antibodies to histones by immunofluorescence. Scand J Immunol 1976; 5: 811 .

12 Johnson P M. IgM-rheumatoid factors cross-reactive with IgG and a cell nuclear antigen: immunopathological implications? Ann Rheum Dis 1980; 39: 586-8.

13 Venables P J W, Smith P R, Maini R N. Purification and characterisation of Sjögren's syndrome $\mathrm{A}$ and $\mathrm{B}$ antigens. Clin Exp Immunol 1983; 54: 731-8.

14 Smith P R, Venables P J W. Williams D W, Maini R N. Identification of a ubiquitous $55 \mathrm{~K}$ polypeptide in the Sjögren's syndrome A antigen. Rheumatol Int 1984; 4: 135-8.

15 Venables P J W, Roffe L M, Erhardt C C. Maini R N. Edwards J M B. Porter A D. Titres of antibodies to RANA in rheumatoid arthritis and normal sera: relationship to EpstcinBarr virus injection. Arthritis Rheum 1981; 24: 1459-64.

16 Venables P J W, Smith P R. Maini R N. Rheumatoid arthritis nuclear antigen and Epstein-Barr virus. Arthritis Rheum 1984; 27: 476-7.

17 Zubler R H, Nydegger U, Perrin L H, et al. Circulating and intra-articular immune complexes in patients with rheumatoid arthritis. J Clin Invest 1976; 57: 1308-19.

18 Chapman J R, Charles P J, Venables P J W, et al. The clinical significance of antibodies to nuclear ribonucleoprotein and other nuclear antigens in cryptogenic fibrosing alvcolitis. $\mathrm{Am}$ Rev Respir Dis 1984; 130: 439-43.

19 Laemmli U K. Clearage of structural proteins during the assembly of the bacteriophage T4. Nature 1970; 227: 680-5.

20 Burnette W N. 'Western blotting': electrophoretic transfer of proteins from SDS-polyacrylamide gels to unmodified nitrocellulose and radiographic detection with antibody and radioiodinated protein-A. Ann Biochem 1981; 112: 195-203.

21 McConahey P S, Dixon F J. A method of trace iodination of proteins for immunologic studics. Int Arch Allergy Appl Immunol 1966; 29: 185-9.

22 Rubin R L, Balderas R S. Tan E M. Dixon F J. Theofilopolous A N. Multiple autoantigen binding capabilities of mouse monoclonal antibodies selected for rhcumatoid factor activity. $J$ Exp Med 1984; 159: 1429-40. 